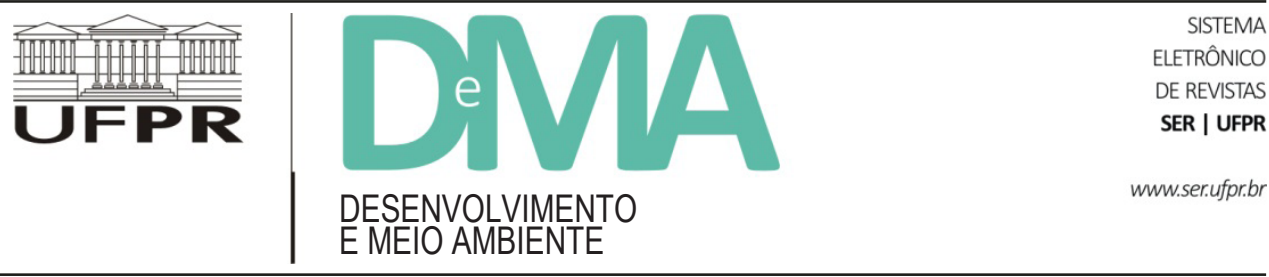

\title{
Percepções sobre os riscos das mudanças climáticas no contexto da região semiárida do Rio Grande do Norte, Brasil
}

\section{Perceptions about the risks of climate change in the context of the semi-arid region of Rio Grande do Norte, Brazil}

\author{
Eric Mateus Soares DIAS ${ }^{1 *}$, Zoraide Souza PESSOA ${ }^{1}$ \\ ${ }^{1}$ Universidade Federal do Rio Grande do Norte, Natal, RN, Brasil. \\ *E-mail de contato: ericmateusemsd@gmail.com
}

Artigo recebido em 25 de abril de 2020, versão final aceita em 20 de setembro de 2020, publicado em 18 de dezembro de 2020.

RESUMO: As mudanças climáticas causadas pela elevação na temperatura média da terra são inequívocas. Essas mudanças expõem diversos sistemas a riscos, como a maior frequência e intensidade de eventos climáticos extremos e a elevação do nível do mar, entre outras ameaças climáticas. Para as regiões semiáridas, as projeções indicam que o clima tenderá a tornar-se mais árido, agravando episódios de seca e aumentando os processos de desertificação. A proposta deste artigo é compreender como formadores de opinião e tomadores de decisão no Estado do Rio Grande do Norte percebem os riscos das mudanças climáticas na região semiárida. A pesquisa apresenta uma abordagem qualitativa, com a realização de estudo de caso e com dados oriundos de levantamento bibliográfico e documental e de entrevistas estruturadas realizadas com representantes de órgãos públicos e pesquisadores. Os resultados apontam que esses atores percebem os riscos das mudanças climáticas como um agravante a ameaças climáticas com histórico de ocorrência no estado. As ameaças percebidas apresentam concordância com as tendências climáticas projetadas pela literatura; com isso, indicam alta probabilidade de ocorrência na área de estudo.

Palavras-chave: clima semiárido; ameaças climáticas; extremos climáticos.

ABSTRACT: The climate changes caused by the rise in the average temperature of the earth are unmistakable. These changes, subject several systems to risks, such as: greater frequency and intensity of extreme climatic events, rising sea levels, among other climate threats. For semi-arid regions, the projections indicate that the climate will become more arid, aggravating drought and increasing desertification processes. The purpose of this paper is to understand how opinion makers and decision makers in the state of Rio Grande do Norte perceive the risks 
of climate change in the semiarid region. The research presents a qualitative approach, with a case study and data from bibliographic, documentary surveys and structured interviews conducted with representatives of public agencies and researchers. The results points that these actors perceived the risks of climate change, as an aggravation to climate threats with a history of occurrence in the state. The perceived threats are in agreement with the climate trends projected by the literature, thus indicating a high probability of occurrence in the study area.

Keywords: semi-arid climate; climate threats; climatic extremes.

\section{Introdução}

As mudanças climáticas impõem o surgimento de novos riscos e, assim, tornaram-se um dos maiores desafios globais deste século (McBean, 2004) e aparecem como a principal discussão sobre meio ambiente em todas as ciências (Ojima \& Mandarola Jr., 2013).

A mudança climática é causada pelo aquecimento global e o aumento da temperatura média da terra nas últimas décadas possui forte influência humana devido à maior concentração de gases de efeito estufa (GEE) na atmosfera. Essas emissões já levaram a um acréscimo de $0,85^{\circ} \mathrm{C}$ na temperatura média da terra entre 1880 e 2012 (IPCC, 2013).

Esse incremento na temperatura já provoca mudanças no sistema climático, que são percebidas pelas alterações nos regimes de chuvas, pelo derretimento do gelo e pela elevação do nível dos oceanos (IPCC, 2007; 2013), assim como pela ocorrência de eventos climáticos extremos, como furacões, tempestades, grandes secas e ciclones. E esses eventos têm ocorrido em áreas incomuns, com maior frequência e maior grau de severidade (Barbieri et al., 2018).

Nesse sentido, é urgente frear o curso do aquecimento da terra para manter o aumento da temperatura abaixo de $2^{\circ} \mathrm{C}$, e isso exige ações de mitigação significativas para redução das emissões e sumidouros de GEE. No entanto, em nível global, o estabelecimento de metas e compromissos nos acordos internacionais para redução das emissões não teve, até então, resultados significativos (Giddens, 2010; Martins \& Ferreira, 2011).

No cenário nacional, o Brasil tinha uma posição de liderança nos debates e nas ações referentes à mitigação das mudanças climáticas (Obermaier \& Rosa, 2013). Porém, desde 2016, é evidente o enfraquecimento das políticas ambientais e os desvios nas ações climáticas, sobretudo pelo governo federal.

Desse modo, mesmo que sejam desenvolvidas ações mais consistentes para frear as emissões em nível global, os riscos das mudanças climáticas já estão se concretizando e irão se agravar, gerando impactos sobre diversas regiões e setores (IPCC, 2007; 2013). E quanto mais vulnerável, mais suscetível ao risco (Marandola Jr. \& Hogan, 2006).

No contexto brasileiro, a região semiárida é considerada por Marengo (2008) uma área bastante vulnerável e, portanto, exposta aos riscos das mudanças climáticas de forma mais intensa. Essa região é caracterizada por uma intensa variabilidade climática natural e marcada por cenários de múltiplas escassezes dos pontos de vista ambiental, social e econômico (Marengo, 2008; Simões et 
al.; 2010), havendo, assim, uma sobreposição de vulnerabilidades.

A partir dessa problemática exposta, esse estudo pretende refletir sobre os riscos das mudanças climáticas sobre a região semiárida, com recorte espacial sobre o Estado do Rio Grande do Norte, cujo clima semiárido representa $93 \%$ do seu território, ou seja, o estado brasileiro com maior porção semiárida. O estado apresenta contextos ambiental, social, econômico, cultural e político semelhantes aos demais estados inseridos nessa região; dessa forma, as reflexões realizadas nesse estudo de caso podem lançar luz sobre uma perspectiva de escala regional.

Face ao exposto, o objetivo deste artigo é compreender como formadores de opinião e tomadores de decisão no estado percebem os riscos das mudanças climáticas na região semiárida do Rio Grande do Norte. Essa pesquisa justifica-se pelo pressuposto de que a percepção dos riscos das mudanças climáticas influencia nas respostas aos seus impactos (Kern \& Alber, 2008). Sendo assim, os resultados aqui apresentados podem subsidiar a compreensão de como os riscos climáticos vêm sendo integrados às gestões ambiental e climática voltadas para a região semiárida, no âmbito de uma pesquisa mais ampla em andamento. Ainda, este estudo pode contribuir para a construção de diretrizes de respostas aos riscos climáticos.

\section{Metodologia}

\subsection{Caracterização da área de estudo}

O Estado do Rio Grande do Norte está localizado na região Nordeste do Brasil, limitando-se com os Estados do Ceará e da Paraíba e é banhado pelo Oceano Atlântico. Sua extensão territorial é de 52,9 mil km², com 167 municípios e 3.168 .027 habitantes (IBGE, 2010). O clima semiárido abrange 49 mil km², ou seja, 93\% do território (Figura 1), compreendendo 147 municípios e com população de 1.922.440 habitantes (SUDENE, 2017).

Em relação às características do clima semiárido, Diniz \& Pereira (2015) argumentam que há variações relacionadas a períodos secos e chuvosos. Sendo assim, algumas regiões diferem quanto aos períodos secos, podendo ser brandos (6 meses), medianos ( 7 a 8 meses) e fortes ( 9 a 10 meses).

Os fatores que influenciam as precipitações e os meses secos em determinadas regiões podem ser melhor aferidos no estudo citado. Contudo, adianta-se que o planalto da Borborema é um dos fatores que apresenta bastante influência quanto aos baixos índices pluviométricos na zona equatorial, principalmente a região Seridó e as áreas de influência da brisa terra/mar, no litoral (Diniz \& Pereira, 2015).

Devido a essas características climáticas, a região semiárida do Rio Grande do Norte, assim como a maior parte do Nordeste Brasileiro, apresenta vegetação do tipo caatinga, representando $75 \%$ do seu território (Nunes, 2006). "É formada por vegetação lenhosa de porte baixo ou médio, com plantas xerófitas, ou seja, adaptadas a lugares secos, e plantas caducifólias, que perdem as folhas para diminuir a transpiração e evitar assim, a perda de água armazenada" (Nunes, 2006, p. 63).

A variação de tipos de climas se reflete também na disponibilidade hídrica do estado, seja nas fontes superficiais ou subterrâneas. Todo o território do estado está enquadrado na região hidrográfica Atlântico Nordeste Oriental, que possui a menor disponibilidade hídrica do país (ANA, 2017). O 


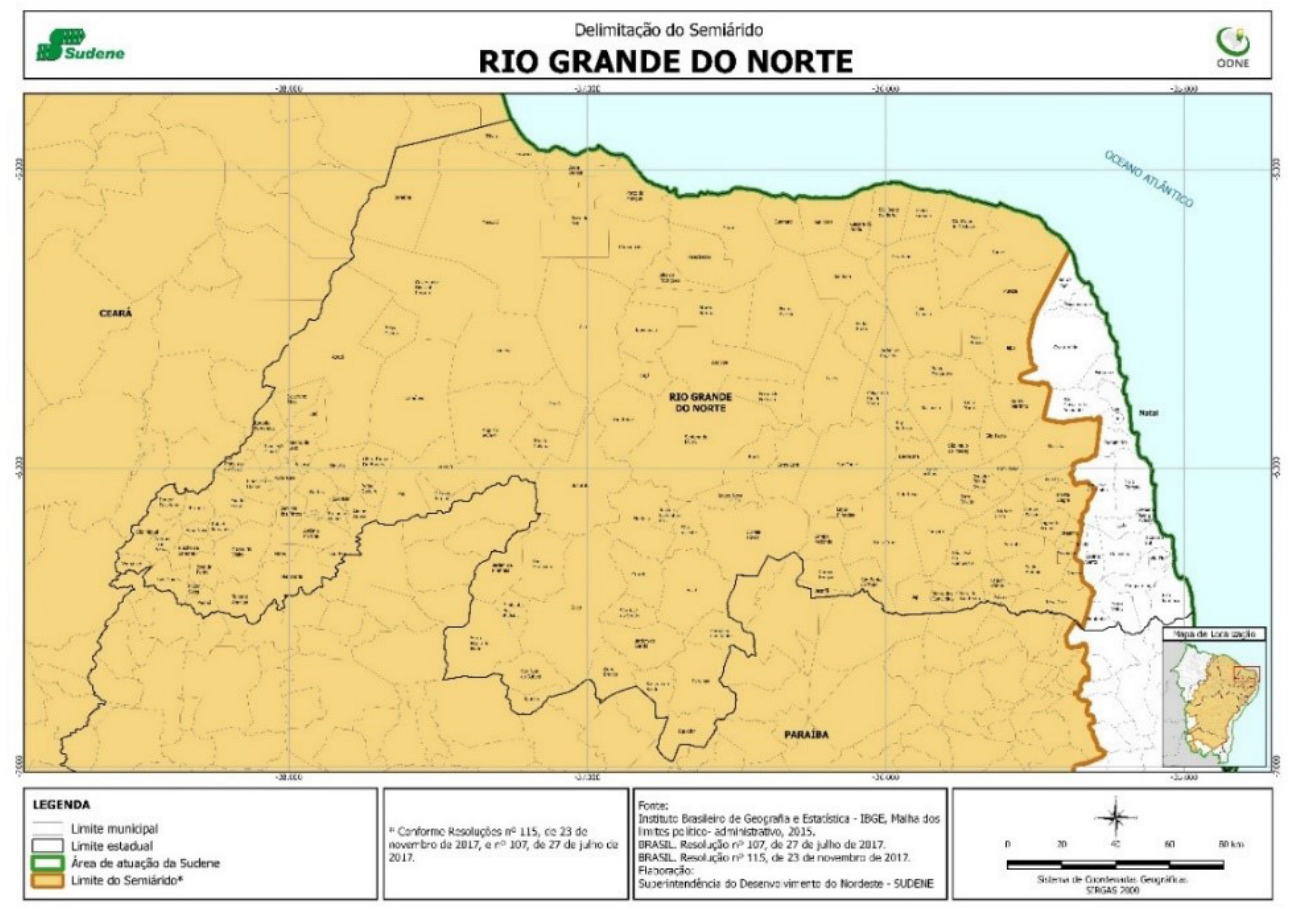

FIGURA 1 - Delimitação do semiárido no Estado do Rio Grande do Norte, Brasil. FONTE: SUDENE (2017).

regime de chuvas anual é concentrado por períodos de três a cinco meses, mas com distribuição irregular no tempo e no espaço, totalizando médias anuais entre 400 e $800 \mathrm{~mm}$. Essas chuvas, normalmente, ocorrem de fevereiro a junho (Ab'Sáber, 1999; Garjulli, 2003), além de apresentar elevadas temperaturas, de $27^{\circ}$ a $29^{\circ} \mathrm{C}$, durante a maior parte do ano (Ab’Sáber, 1999; Cirilo et al., 2010).

Apesar dessas limitações climáticas, desde a colonização a rica base de recursos naturais do estado propiciou o desenvolvimento de atividades agropecuárias e extrativistas. Até meados da década de 1960, sua estrutura produtiva ainda apresentava o perfil de uma típica economia agroexportadora
(Carvalho, 2014). E, a partir dos anos 1970/80, houve uma crescente dos setores secundário e terciário, com destaque para a indústria do petróleo, que alavancou o PIB estadual com taxas superiores às médias regional e nacional (Aquino \& Nunes, 2019).

Um rol de políticas sociais de combate à pobreza, de investimentos públicos federais e privados em infraestrutura garantiu ao $\mathrm{RN}$ e ao nordeste uma trajetória de crescimento até as duas primeiras décadas do século XXI. Contudo, esse crescimento, historicamente, é marcado por uma grande desigualdade entre os municípios do estado, com riquezas concentradas na região metropolitana 
de Natal e municípios interioranos com atividades de dinâmica econômica global (Aquino, 2016).

Depois disso, a economia do RN passa a crescer menos do que a média do país e do Nordeste e entra em recessão a partir de 2014 (Aquino \& Nunes, 2019) e em um contexto de pobreza e desigualdades, que sempre foi uma realidade latente no estado (Villas Bôas, 2018). Assim, a economia do $\mathrm{RN}$ apresenta um cenário futuro de desafios e incertezas, que exige ações políticas para retomar o crescimento e que integrem a região semiárida, dessa forma garantindo a inclusão social, a sustentabilidade e a diminuição de desigualdades.

Isso, evidentemente, é possível pelas potencialidades dos municípios interioranos da região semiárida que, além de potencial para agropecuária, apresentam um cenário de expansão econômica em atividades como a fruticultura irrigada, a carcinicultura, o extrativismo mineral, o turismo e, mais recentemente, as energias renováveis eólica e solar. Porém, tudo isso exige mudanças estruturais e políticas, sobretudo para superar as limitações climáticas, econômicas e sociais.

\subsection{Percursos metodológicos}

Esta pesquisa adota uma abordagem de pesquisa exploratória e descritiva com caráter qualitativo, utilizando-se dos métodos de estudo de caso e entrevistas para uma compreensão mais aprofundada do problema a que se propõe resolver (Minayo \& Sanches, 1993; Franco, 2003), possibilitando, assim, retratar a realidade e as múltiplas dimensões que interagem para condicionar o risco das mudanças climáticas sobre a região semiárida do Rio Grande do Norte.
Os resultados e discussões aqui apresentados foram desenvolvidos em três fases: a primeira foi exploratória, de consulta a bibliografias e coleta de dados secundários; a segunda foi a etapa de campo, com a realização de entrevistas estruturadas; e a terceira foi a etapa de sistematização, análise e interpretação dos dados.

A primeira fase possibilitou a revisão de conceitos-chave e compreender a área estudada em seus diversos aspectos: ambiental, social, econômico, político e institucional, a partir do levantamento bibliográfico e documental em artigos, livros, sites, relatórios, leis e planos em órgãos e instituições, tais como: Instituto de Gestão das Águas do Rio Grande do Norte (IGARN), Secretaria de Meio Ambiente e Recursos Hídricos (SEMARH), Defesa Civil Estadual (DC), Instituto de Desenvolvimento Sustentável e Meio Ambiente (IDEMA), Instituto Brasileiro de Geografia e Estatística (IBGE), entre outras. Essa fase compreendeu todo o período de realização da pesquisa.

A segunda fase, de realização das entrevistas, foi fundamental para compreender a percepção dos entrevistados sobre os riscos e ocorreu entre novembro de 2019 e fevereiro de 2020 . Foram entrevistados 14 indivíduos, divididos em dois grupos: um com sete pesquisadores (UFRN, UERN, UFER$\mathrm{SA}$ ), composto por pós-graduandos e professores que desenvolvem pesquisas sobre meio ambiente, mudanças climáticas e recursos hídricos e que já tiveram experiência de atuação em órgãos ambientais públicos, portanto, são/foram atores importantes na formação de opinião, e outro com sete representantes de órgãos públicos (Defesa Civil, SEMARH, IDEMA, IGARN), composto por técnicos, gestores e líderes importantes para tomada de decisão sobre as questões ambientais e climáticas no estado. As 
entrevistas foram orientadas por um roteiro prévio com perguntas abertas, tiveram duração média de 45 minutos e foram gravadas com a permissão do entrevistado.

Ressalta-se que, no âmbito desta pesquisa, entende-se por percepção o que Forgus (1971, p. 1-2) descreveu como "processo de extrair informação". Partiu-se do princípio de que a compreensão da percepção de representantes dos órgãos públicos e pesquisadores sobre os riscos climáticos indicaria o conhecimento sobre os riscos climáticos e as respostas que vêm sendo dadas a eles no âmbito da área estudada. Contudo, o desenvolvimento de ações de resposta e os mecanismos de adaptação climática serão análises feitas no âmbito de uma pesquisa mais ampla.

A terceira fase, de análise e discussões dos dados, ocorreu entre fevereiro e abril de 2020. Para isso, optou-se pelo uso da técnica de análise de conteúdo, que proporcionou uma compreensão crítica sobre o conteúdo explícito ou oculto dos dados coletados, respaldando-se em Bardin (1977).

Para efeito desta análise, foi criada a categoria de análise "ameaças climáticas", que foi previamente definida para realização das entrevistas e será melhor explicada no tópico 4. Para facilitar o entendimento dos entrevistados acerca dessa categoria, utilizou-se algumas palavras-chave (tendências, projeções, impactos). Essa categoria foi utilizada para identificar a quais ameaças climáticas a área de estudo está/estará sujeita, a partir da percepção dos participantes, já que a ameaça é um fator que determina o risco climático.

\section{Os riscos das mudanças climáticas para região semiárida brasileira}

O aquecimento global é inequívoco, sendo consenso entre os cientistas, que o aumento da concentração de gases de efeito estufa (GEE) na atmosfera aumenta a temperatura global (Carter, 2007). Esse aumento deve-se, principalmente, às emissões do dióxido de carbono $\left(\mathrm{CO}_{2}\right)$, pela queima de combustíveis fósseis e pelas mudanças do uso da terra, e às emissões do gás metano $\left(\mathrm{CH}_{4}\right)$, pela agropecuária e pela queima de biomassa (IPCC, 2007, 2013).

Sabe-se que o efeito estufa é o fenômeno natural que acumula os gases na atmosfera e é fundamental para garantir a temperatura necessária para a manutenção da vida no planeta. No entanto, vem ocorrendo rápido aumento na temperatura média da terra, observado desde a revolução industrial. Há, portanto, uma aceitação de $95 \%$ de probabilidade de que esse aquecimento seja resultante das atividades humanas, principalmente industriais, de consumo de energia, agropecuária, desmatamento, uso e ocupação do solo, concentração urbana, entre outras ações, de maneira integrada, que têm contribuído para as mudanças climáticas globais (Carter, 2007; IPCC, 2007, 2013).

A mudança climática é definida pelo IPCC como "uma variação estatisticamente significativa nas condições médias do clima ou em sua variabilidade, que persiste por um longo período - geralmente décadas ou mais" (IPCC, 2007). Nesse trabalho,

Essa categoria e a sistematização dos dados foram desenvolvidas com base no texto Método de análise participativa de risco à mudança do clima, elaborado no âmbito do Projeto Biodiversidade e Mudanças Climáticas na Mata Atlântica, coordenado pelo Ministério do Meio Ambiente (Brasil, 2018). 
usa-se esta definição considerando a mudança climática como consequência direta ou indireta das atividades humanas e que altera a variabilidade climática, atribuída às causas naturais, em escala local (UNFCCC, 1992).

As projeções realizadas pelo IPCC, de mudanças futuras na temperatura, são geradas por modelos climáticos ${ }^{2}$ que consideram vários cenários ${ }^{3} \mathrm{de}$ emissão de gases de efeito estufa e de desenvolvimento socioeconômico. O quarto relatório do IPCC (2007), apresentou quatro cenários chamados de "Representative Concentration Pathways" (RCPs): RCP2.6, RCP4.5, RCP6.0 e RCP8.5.

O RCP8.5 é considerado o pior cenário, em que nenhuma medida efetiva em escala global para limitar as emissões será tomada; assim, até o ano de 2100 alcançará um aumento de até $4^{\circ} \mathrm{C}$ na temperatura média da Terra. Na medida em que ações de contenção das emissões forem desenvolvidas, os cenários melhoram e as projeções de aumento de temperatura diminuem. Então, o RCP2.6 seria o melhor cenário, onde haveria o máximo comprometimento em frear as emissões e um aumento de até $1^{\circ} \mathrm{C}$ (IPCC, 2013).

Apesar das diversas incertezas associadas a esses cenários climáticos possíveis - pois o clima variou naturalmente em todas as escalas temporais e espaciais ${ }^{4}$ (IPCC, 2007), é necessário entender que "nas últimas duas décadas, a superfície está aquecendo quase $0,2^{\circ} \mathrm{C}$ por década, que é um ritmo 50 vezes mais acelerado do que o ciclo natural glacial-interglacial" "(Nobre et al., 2012, p. 8). Sendo assim, a velocidade e a intensidade em que ocorre o aumento da temperatura nesse período devem estar associadas a fatores antrópicos que incidem sobre o sistema climático.

Entretanto, a mudança climática só passou a ser percebida como um risco ambiental global e colocada na pauta na agenda política global a partir da década de 1970, em que o avanço da computação permitiu que os cientistas desenvolvessem modelos muito mais sofisticados, que, embora ainda sujeitos a incertezas, levaram a um aumento da confiança dos cientistas nas previsões sobre o aquecimento global (Bodansky, 2001; Lindoso, 2015).

Assim como, pela influência da ascensão das questões ambientais no debate político, colocou-se como emergência a necessidade de modelos de desenvolvimento que gerassem menos impactos ao meio ambiente (Speth \& Tchernov, 2002). Vale citar que a Conferência de Estocolmo, na Suécia, que ocorreu em 1972, reuniu vários países para discutir um futuro mais sustentável e já colocava em discussão a necessidade de proteção da camada de

\footnotetext{
2 Os modelos climáticos conseguem separar as consequências da emissão dos gases de efeito estufa e a variabilidade natural do clima. Isso permite demonstrar que somente a variabilidade natural inerente às condições do tempo não explica o aumento da temperatura observado nas últimas décadas. Somente pelo acoplamento de análises estatísticas e da prática da modelagem computacional é que os cientistas se tornaram hábeis para isolar e demonstrar a contribuição das ações humanas para o aquecimento do clima global (Weart, 2003).

${ }^{3}$ Os cenários climáticos sugerem possibilidades sobre como o clima poderia ser no futuro caso as medidas que interferem nas emissões futuras de GEE fossem cumpridas (Ambrizzi \& Lacerda, 2012).

${ }^{4}$ Isso pode ser percebido no acompanhamento da variação climática da Terra nos últimos 800 mil anos, no estudo de Hansen \& Sato, 2012.

${ }^{5}$ Um período interglacial é um intervalo geológico caracterizado por temperaturas médias mais quentes que separam os períodos glaciares. Há 120 mil anos, tivemos o último período interglacial mais conhecido e mencionado na literatura, onde a temperatura estava um pouco acima da temperatura atual (Nobre et al., 2012).
} 
ozônio. E foi em 1988 que houve o reconhecimento oficial, pela assembleia da Organização das Nações Unidas (ONU), da mudança climática como uma preocupação comum da humanidade (Bodansky, 2001).

Um marco para o desenvolvimento de pesquisas sobre o clima acontece nesse mesmo ano, com a criação do Painel Intergovernamental sobre Mudança Climática (IPCC) sob o comando da Organização Mundial de Meteorologia (OMM) e do Programa das Nações Unidas para o Meio Ambiente (PNUD), que reúne cientistas de vários países, a fim de fornecer informações científicas, técnicas e socioeconômicas relevantes para o entendimento da mudança do clima para a sociedade e para os formuladores de políticas (ONU, 2019). O IPCC consolida essas informações em relatórios periodicamente publicados e publicações especiais. O primeiro relatório de avaliação foi publicado em 1991; o segundo, em 1995; o terceiro, em 2001; o quarto, em 2007; o quinto, em 2014 e tem a publicação do sexto relatório prevista para 2022.

No cenário nacional, a institucionalização do debate sobre mudanças climáticas se efetivou com a instituição da Política Nacional sobre Mudança do Clima (PNMC), pela Lei no $12.187 / 2009$, com diretrizes que apontam para a promoção do desenvolvimento de pesquisas científico-tecnológicas para identificação de vulnerabilidades e adoção de medidas de mitigação e adaptação adequadas nos âmbitos local e regional (Brasil, 2009).

Seguindo os moldes do IPCC, foi criado em 2009 o Painel Brasileiro de Mudanças Climáticas (PBMC), como um organismo científico composto por centenas de pesquisadores, para reunir, sintetizar e avaliar informações científicas sobre os impactos relevantes das mudanças climáticas no Brasil e publicar relatórios de avaliação nacional. Os resultados do primeiro Relatório de Avaliação Nacional do PBMC, publicado em 2013, reforçam as projeções de aumento de temperatura e de frequência de eventos extremos apresentadas no Quinto Relatório de Avaliação do IPCC (PBMC, 2013).

Tanto o IPCC como o PBMC contribuem para o fornecimento de conhecimento para definição de políticas para dar respostas às mudanças climáticas nos diversos setores e no contexto brasileiro; contudo, ainda há muitas incertezas sobre as formas diversas dos seus possíveis impactos e sua magnitude, tanto temporal quanto espacial. Essas incertezas são relacionadas às projeções climáticas e envolvem diversos fatores, como os inúmeros componentes do sistema climático; as variações naturais não lineares; os cenários de emissão, entre outros (Knutti et al., 2010).

Além do aperfeiçoamento nas ciências climáticas, com vistas a produzir modelos climáticos cada vez mais consistentes e diminuir as incertezas, o campo de investigação das dimensões humanas das mudanças climáticas globais emerge como uma proposta interdisciplinar de análise para desenvolver e aplicar modelos teórico-conceituais entre temas transversais e intrínsecos ao debate das mudanças climáticas, como, por exemplo, as abordagens sobre vulnerabilidades, riscos e capacidade adaptativa (Marandola Jr. \& Hogan, 2006; Martins \& Ferreira, 2010, 2011).

O presente trabalho não pretende esgotar ou estender o assunto sobre esses temas, mas busca sintetizar questões conceituais e suas possíveis aplicações para metodologia e análises desse estudo. É bastante evidente que, diante do cenário de aumento da intensidade e da frequência de eventos climáticos extremos ocasionados pelas mudanças 
climáticas, há uma tendência em acentuar as situações de vulnerabilidades e riscos sobre os diversos sistemas da Terra (Hogan, 2001).

Nesse contexto, existem múltiplas concepções para abordar a vulnerabilidade, porém, nesse estudo adota-se a vulnerabilidade como uma condição interna de um determinado sistema, independentemente do perigo climático em questão (Adger \& Kelly, 1999; Veyret, 2013). Essas condições são determinadas por fatores físicos, sociais, econômicos ou ambientais que influenciam ou aumentam a suscetibilidade do sistema aos riscos (UNISDR, 2007; 2009).

No contexto das mudanças climáticas, fatores como crescimento populacional, pobreza, degradação ambiental, escolaridade, habilidades, condições de saúde, idade e outras características culturais e sociais são citados como condições que ampliam a vulnerabilidade aos riscos das mudanças climáticas (Martins et al., 2004; IPCC, 2007; 2013).

Os riscos das mudanças climáticas somam-se aos inúmeros riscos enfrentados pelas sociedades contemporâneas, que são os riscos naturais, ambientais, industriais, sociais e econômicos (Veyret, 2013). Essa sobreposição de riscos caracteriza a sociedade global de risco (Beck, 2010). As mudanças climáticas, por sua vez, estão incluídas na perspectiva dos riscos ambientais, em que Veyret (2013) considera que esses resultam da associação entre riscos naturais e os riscos agravados pela ação do homem.

Em torno da temática do risco há uma polifonia de conceitos (Marandola Jr., 2009). No âmbito desse trabalho, entende-se que o risco está associado às noções de probabilidade, de magnitude e de incerteza da concretização de impactos adversos e de um estado indesejável (IPCC, 2001; UNISDR, 2007;
2009; Zanirato et al., 2008), que possam ocorrer como resultado de eventos naturais ou atividades humanas (Kates et al., 1985). Beck (2010) colabora nesse entendimento, argumentando que os riscos são consequências da industrialização e globalização.

Zanirato et al. (2008) fazem uma profunda crítica, afirmando que a sociedade passou a gerar o risco e a naturalizar a convivência com ele e seus impactos. De certa forma, a convivência com os riscos das mudanças climáticas será uma condição, pois, mesmo com a estabilização das concentrações de GEE, o aumento da temperatura e o avanço do nível do mar continuarão por séculos, devido às escalas de tempo associadas aos processos existentes no sistema climático e realimentações (IPCC, 2007).

Outro aspecto importante para a definição do risco é a percepção que se tem dele, considerando que o risco não pode ser definido apenas como a efetivação dos impactos negativos, mas também como resultado da interpretação que se tem dele (Kasperson et al., 2003). Beck (2010) complementa que o risco é um fenômeno socialmente construído e nem todos conseguem percebê-lo.

Para Yearley (2009), a construção social dos riscos das mudanças climáticas é definida pelas projeções da situação do clima futuro, pelas suposições de como as pessoas, o governo e as corporações se comportarão futuramente, bem como pelos interesses institucionais para legitimação das projeções e ações de respostas aos riscos.

A compreensão da percepção dos riscos é um aspecto de suma importância na construção da análise desse trabalho, considerando que a tomada de decisões no âmbito das mudanças climáticas tem forte influência na forma pela qual os indivíduos percebem os riscos a que estão expostos (Kern \& Alber, 2008). Leiserowitz (2006) salienta que há 
uma grande diferença entre a percepção da sociedade civil, dos especialistas e dos governantes sobre os riscos associados às mudanças climáticas.

A distinção dos riscos naturais e dos riscos das mudanças climáticas é bastante complexa. Segundo Giddens (2010), os riscos das mudanças climáticas são fabricados, ou seja, criados pelo homem, porém, se manifestam na forma de riscos naturais. Por exemplo, as inundações, as tempestades e as secas são riscos ambientais naturais que podem, também, ser resultados das mudanças climáticas ou que podem ser intensificados por elas.

Tendo em vista que o clima já apresenta alterações, os riscos das mudanças climáticas, possivelmente, já estão se materializando na forma de desastres ambientais, como grandes inundações, secas extremas incomuns em algumas regiões e de maior proporção em outras, furacões, entre outros, causando grandes perdas humanas e materiais, afetando a qualidade de vida e o desenvolvimento (Nunes, 2009; Barbieri et al., 2018). Contudo, Beck (2010) afirma que, apesar de os riscos climáticos afetarem as populações em escala global, seus efeitos são sentidos de forma desigual, com impactos mais severos em populações mais vulneráveis e com baixa capacidade de resposta.

Os riscos da mudança climática poderão induzir a mudanças na frequência, na intensidade, na dimensão espacial e na duração de eventos climáticos, resultando em extremos sem precedentes e com efeitos adversos em diversos sistemas, sobretudo aos recursos hídricos, que impõem consequências negativas às populações (IPCC, 2013; Veyret, 2013).

Nesse contexto, Marengo (2008) enfatiza o semiárido brasileiro como uma área de risco e bastante vulnerável às mudanças climáticas futuras, porque apresenta territórios historicamente marcados pela ocorrência de eventos extremos de seca e pelos cenários de múltiplas vulnerabilidades dos pontos de vista climático e socioeconômico e que muitas vezes se sobrepõem, potencializando os riscos.

Isso pode também ser evidenciado pelas projeções de clima para essa região, que sugerem um aumento considerável na temperatura e, consequentemente, maior ocorrência de eventos extremos de secas e estiagens prolongadas. Esse aumento de temperatura irá se acentuar a partir da metade e do final do século XXI, e no final do século pode atingir condições significativamente mais quentes, com elevações de temperatura entre $3,5^{\circ}$ e $4,5^{\circ} \mathrm{C}$ (PBMC, 2013).

É possível afirmar, portanto, que é por meio dos recursos hídricos que primeiramente as populações e os setores usuários sentirão os efeitos das mudanças climáticas no semiárido, devido às mudanças no ciclo hidrológico em função da evolução dos padrões da precipitação (aumento da intensidade e da variabilidade), que poderão afetar significativamente a disponibilidade e a distribuição temporal da vazão nos rios para além dos fatores de pressão antrópica em percurso (Brasil, 2016).

Na região semiárida, a disponibilidade hídrica sempre apresentou diversas limitações devido às condições climáticas de semiaridez. Contudo, os relatórios do IPCC $(2007 ; 2013)$ alertam que o clima apresenta grande tendência a tornar-se mais árido e aumentarão a frequência e a intensidade das secas, dificultando ainda mais a recarga dos mananciais (Ambrizzi et al., 2007). Além das secas, há projeções de maior ocorrência de chuvas torrenciais, perdas de biodiversidade, modificação do bioma caatinga e aceleração do processo de desertificação (IPCC, 2007; Marengo, 2008; 2014). 
Em síntese, a diminuição da quantidade e qualidade dos recursos hídricos podem afetar a produção de alimentos, principalmente, pelos agricultores familiares; a qualidade dos ecossistemas; a saúde, com a propagação de doenças de veiculação hídrica; o abastecimento humano e operação da infraestrutura hídrica (Kundzewicz et al., 2007).

Como pode ser observado, as mudanças climáticas despontam como um problema complexo e apresentam um elevado grau de incerteza para a definição das ações a serem tomadas face aos riscos que provocam. A despeito dessas incertezas, é de fundamental importância que os riscos sejam percebidos como um problema ambiental público e que é preciso adaptar-se aos seus possíveis impactos, sejam eles ocasionados pela variabilidade natural do clima ou pelas mudanças climáticas agravadas pelo homem.

\section{Os riscos das mudanças climáticas sobre a região semiárida do Rio Grande do Norte: percepções de pesquisadores $e$ representantes de órgãos públicos}

No contexto dessa análise, entende-se por risco a probabilidade de consequências danosas a sistemas de interesse (economia, perdas humanas, ambiental, infraestruturas), pela interação entre as ameaças naturais e/ou antropogênicas e as situações de vulnerabilidade de um sistema exposto (Cardona, 1993). O IPCC (2014) enfatiza o risco como resultado da interação entre sensibilidade, exposição e ameaças climáticas.

Portanto, a ameaça climática foi a categoria escolhida para fazer a análise sobre os riscos climáticos a que a área de estudo está/estará sujeita. Por ameaça climática, entende-se que é a potencial ocorrência de um evento, tendência climática ou seus impactos físicos. Cardona (2004) reitera que a ameaça se refere a um perigo latente ou fator desfavorável externo a que um sistema ou indivíduo está exposto.

As reflexões sobre os riscos das mudanças climáticas na região semiárida do $\mathrm{RN}$ foram feitas a partir da percepção de pesquisadores e de representantes de órgãos públicos sobre as ameaças climáticas. Ainda, foram averiguados a concordância da literatura e os relatórios de avaliação do IPCC e PBMC, com as ameaças percebidas pelos participantes da pesquisa.

Primeiramente, os participantes foram questionados sobre o que entendem a respeito das mudanças climáticas e foi recorrente, nas falas de ambos grupos, que suas opiniões eram baseadas no que é divulgado na literatura especializada, especialmente nos relatórios do IPCC, corroborando Giddens (2010), que afirmou que os riscos das mudanças climáticas só passaram a ser reconhecidos e difundidos no discurso público pela ampla divulgação dos relatórios científicos do IPCC.

Ademais, todos concordam que as ações humanas são as principais deflagradoras do aquecimento global. Porém, alguns ainda apresentam dúvidas sobre a efetivação dos riscos das mudanças climáticas no presente, principalmente se a ocorrência ou o agravamento de alguns eventos climáticos nas últimas décadas estão relacionados às mudanças climáticas.

O que eu sei é a partir do que eu leio, e onde eu busco me informar sobre o tema é no Painel Intergovernamental das Mudanças Climáticas, que reúne especialistas do mundo todo. E essas pesquisas mostram que há uma tendência no clima sofrer mudanças e há um consenso mundial de que essas mudanças estão 
sendo causadas por algumas atividades antrópicas. Particularmente, eu não saberia dizer se essas mudanças que estamos experimentando de alguns eventos climáticos, seriam em função das mudanças climáticas. Por exemplo, a gente vivenciou o maior período de seca no semiárido nos últimos anos, não consigo afirmar se isso é mudança climática ou só um evento de variabilidade natural, acho que precisa de mais anos de observação (Pesquisador/a, 2019).

Tudo que a gente sabe sobre mudanças climáticas é o que a gente ver na literatura, apesar de ser uma incógnita como acontecerão, a gente entende que o que tá posto, que é que as mudanças climáticas têm como consequência o aumento de extremos climáticos, tanto de seca, quanto de quadras chuvosas. Sem falar no aumento do nível do mar, que tá intensificando a erosão costeira marinha. (...) Então vamos ter aumento de inundações, de rompimento de barragens, cidades em colapso hídrico e sem água pra produção... A gente trabalha as mudanças climáticas na perspectiva do agravamento, de um elemento complicador a eventos que já acontecem aqui no estado (Órgão Público, 2019).

Como pode ser visto na fala desses indivíduos, a percepção que se tem dos riscos impostos pelas mudanças climáticas é no sentido do agravamento de ameaças já existentes e observadas por eles. Contudo, Kasperson et al. (2003) salientam que o risco não é percebido apenas pela experiência dos danos físicos, mas pelo processo de aprendizado dos indivíduos sobre os riscos. Sendo assim, pode-se dizer que os riscos são percebidos pelos participantes dessa pesquisa tanto na perspectiva da vivência de ameaças climáticas quanto do conhecimento construído sobre tais questões.

Baseando-se em Beck (2010), os riscos climáticos podem ser reconhecidos pela antecipação, no presente, de catástrofes futuras; portanto, os participantes da pesquisa têm a percepção das possíveis ameaças climáticas que poderão acontecer em virtude das mudanças climáticas.

Isso pode ser evidenciado quando foram questionados sobre quais ameaças climáticas estão afetando ou poderão afetar a região em análise, onde os participantes basearam-se no contexto de suas experiências e vivências, apresentando ameaças climáticas que, historicamente, ocorrem no estado e que podem ser agravadas pelas mudanças climáticas. Dessa forma, apresentaram tendências como: colapso hídrico, crise hídrica, secas, cheias, chuvas torrenciais, aridização, entre outras. Porém, achou-se pertinente unificar algumas tendências apresentadas (por ex.: secas, estiagem e falta de água, optou-se por nomear "extremos de seca").

Assim, após a análise das entrevistas, foi possível perceber que os participantes citaram em comum nove (9) ameaças climáticas: aumento de temperatura, extremos de seca, extremos de chuva, extremos de calor, evapotranspiração, desertificação, incêndios, elevação do nível do mar e perdas de biodiversidade. Adiante, discute-se como cada uma dessas ameaças é percebida pelos participantes da pesquisa e se há concordância com a literatura sobre essas ameaças em escala global, na região semiárida brasileira e na região semiárida do Rio Grande do Norte, em particular.

\subsection{Aumento de temperatura}

O aumento de temperatura é percebido como a ameaça que vai desencadear as demais. Essa ameaça já é bastante massificada na percepção deles e ficou claro em suas falas que eles consideram que esse aumento já vem ocorrendo. 
Todos os setores serão afetados com o aumento da temperatura, porque a gente está em uma casa comum, o que se faz aqui, vai ter consequências aqui. Então, os recursos hídricos, a fauna, a flora e a própria espécie humana estão comprometidas se não forem tomadas providências para conter $o$ aquecimento da terra (Órgão Público, 2019).

Um aumento de temperatura na região semiárida apresenta uma ameaça, no sentido da intensificação dos extremos. A pesar do fenômeno da seca no semiárido ser resultado de fatores climáticos naturais, os relatórios do IPCC mostram que essas mudanças no clima afetam esses fatores e podem intensificar as secas. (...) E o aumento apresentado desde a revolução industrial já está incidindo sobre extremos de precipitação aqui na região, pois as secas estão acontecendo com mais frequência e as chuvas intensas, também (Pesquisador/a, 2019).

A percepção clara sobre essa ameaça se dá pelo amplo discurso difundido na ciência. Atualmente, o aquecimento significativo da atmosfera e dos oceanos é um dado que não oferece margem para qualquer dúvida, sendo que relativamente ao período de 1880 a 2012 a temperatura global calculada por uma tendência linear apresenta um aumento de cerca de $0,85^{\circ} \mathrm{C}$ (IPCC, 2014).

Em relação às considerações sobre o futuro, o aumento da temperatura global depende do cenário de emissões de gases de efeito estufa. O cenário mais otimista prevê que o aumento da temperatura terrestre poderia variar entre $0,3^{\circ} \mathrm{C}$ e $1,7^{\circ} \mathrm{C}$ de 2010 até 2100. O segundo cenário prevê o aumento da temperatura terrestre entre $1,1^{\circ} \mathrm{C}$ e $2,6^{\circ} \mathrm{C}$. No terceiro cenário, o aumento da temperatura varia de $1,4^{\circ} \mathrm{C}$ até $3,1^{\circ} \mathrm{C}$. Já o pior cenário, no qual as emissões continuam a crescer em ritmo acelerado, prevê que a superfície da terra poderia aquecer entre $2,6^{\circ} \mathrm{C}$ e $4,8^{\circ} \mathrm{C}$ ao longo deste século (IPCC, 2013).
No Brasil, aponta-se o aumento de temperatura até 2100 entre $1^{\circ} \mathrm{C}$ e $6^{\circ} \mathrm{C}$, em comparação à registrada no fim do século XX, com aumento gradativo e variável da temperatura média em todas as regiões do país. Na região Nordeste deve ocorrer um aumento relativamente baixo na temperatura - entre $0,5^{\circ} \mathrm{C}$ e $1^{\circ} \mathrm{C}$ - até 2040 . Entre 2041 e 2070, o aquecimento do clima da região deverá ser de $2^{\circ} \mathrm{C}$ a $3^{\circ} \mathrm{C}$. Já para o final do século - entre 2071 e 2100 -, estimam-se condições de aquecimento intenso - com aumento de $3^{\circ} \mathrm{C}$ a $4^{\circ} \mathrm{C}$ na temperatura (PMBC, 2013).

De acordo com Nímer (1979), também se baseando em índices de diferentes autores, no Rio Grande do Norte ocorrem apenas climas quentes, ou seja, com temperaturas superiores aos $18^{\circ} \mathrm{C}$. Segundo Gilmar Bristot, Meteorologista da Empresa de Pesquisas Agropecuárias do Rio Grande do Norte-EMPARN, há uma tendência de verões mais quentes no estado, "enquanto as mínimas chegavam até $22^{\circ} \mathrm{C}$ na década de 70 e 80 , hoje dificilmente se observa temperatura inferior a $24^{\circ} \mathrm{C}$ " (Tribuna do Norte, 2018).

\subsection{Extremos de seca e chuva}

Para os participantes da pesquisa, o aumento de temperatura incide com maior frequência e intensidade em eventos climáticos extremos, tanto de secas quanto de chuvas. As mudanças climáticas, para eles, são agravantes que tornarão ainda mais complexos os problemas já vivenciados no semiárido.

\begin{abstract}
A seca extrema ameaça porque a gente ainda não tem um sistema de gestão eficiente para atender as demandas e faça chegar água a quem precisa. E extremo de chuva não temos um sistema drenagem para escoar água da chuva (Pesquisador/a, 2019).
\end{abstract}


Está havendo uma redução das chuvas, elas estão mais espaçadas, mais localizadas. Já não tem mais estações chuvosas em todo território. Por exemplo, em 2019 tivemos chuva no Seridó, mas em Currais Novos e parelhas no Seridó não choveu e não houve recarga (Pesquisador/a, 2019).

As enxurradas também ameaçam, porque causam o rompimento de reservatórios, porque aqui no estado tem vários pequenos reservatórios mal construidos e mal dimensionados que não suportam a carga de um volume de chuvas alto em curto período (Órgão Público, 2019).

Nas falas dos participantes é possível observar a relação feita entre as ameaças climáticas e os impactos que acarretam. Os participantes trouxeram vários exemplos de danos que podem ocorrer a partir dos extremos de chuva e seca. Apesar dos extremos de secas serem apontados com mais frequência, os extremos de chuva foram citados devido ao histórico de ocorrência de chuvas intensas em algumas regiões do semiárido.

$\mathrm{Na}$ literatura não há projeções globais uniformes relacionadas a extremos de seca e chuva. Para Marengo (2014), as incertezas sobre o comportamento futuro do clima são especialmente significativas no que se refere ao que acontecerá com o ciclo hidrológico, principalmente no hemisfério sul. Contudo, as projeções mostram que na região Sul do Brasil e na bacia do Prata as chuvas vão aumentar, e no leste da Amazônia e no Nordeste haverá redução (IPCC, 2013; Marengo, 2014).

Em relação às precipitações no Brasil, uma das conclusões é que os eventos extremos de secas e estiagens prolongadas, principalmente nos biomas da Amazônia, cerrado e caatinga, devem aumentar e essas mudanças devem se acentuar a partir da metade e no fim do século 21 (PBMC, 2013). Especificamente no Nordeste, as chuvas diminuirão entre $10 \%$ e $20 \%$ até 2040 ; entre 2041 e 2070 , o padrão de chuva irá diminuir entre $25 \%$ e $35 \%$; e até o final do século, se a temperatura aumentar progressivamente, a ocorrência de chuva poderá diminuir entre $40 \%$ e $50 \%$ (PBMC, 2013).

No RN, Lucena et al. (2018) fizeram uma análise hidroclimatológica, chegando à conclusão que muitos municípios apresentam características climáticas semelhantes, com baixas taxas de precipitação e forte variabilidade temporal e espacial das mesmas. Visto isso, os períodos de seca (baixo volume de precipitação) no estado afetam 75\% dos municípios, que, de um modo geral, apresentam precipitações relativamente baixas, com médias anuais inferiores aos 784,4 $\mathrm{mm}$.

\subsection{Extremos de calor}

Os extremos de calor foram citados como o resultado do aumento de temperatura e dos extremos de seca, que causariam máximas nas temperaturas locais e um forte desconforto térmico, principalmente em locais mais urbanizados.

As ondas de calor são muito preocupantes, a gente percebe que cada vez mais os dias têm sido mais quentes, até mesmo aqui em Natal. Tem dias que faz um calor insuportável... E a gente sabe que os extremos de calor podem causar mortes. Então a gente já tem uma temperatura elevada no semiárido, ai imagina se houver um acréscimo? É bastante preocupante (Órgão Público, 2019).

Os eventos extremos são o que os cientistas apontam como maior sintoma das mudanças climáticas. Então eu acho que isso já tá ocorrendo... As ondas de calor 
aqui no Nordeste, aqui em Mossoró, no Ceará... Tá insuportável! E eu posso afirmar que antes não era desse jeito. Hoje ninguém fica em casa sem, no mínimo, um ventilador (Órgão Público, 2020).

Seguindo as tendências de aumento da temperatura, segundo o IPCC (2007), em muitas áreas do globo, dias e noites quentes têm sido mais intensos e frequentes e as perspectivas para o futuro são de manutenção destas tendências.

No Brasil, em um estudo feito por Bitencourt et al. (2016), foram identificadas ondas de calor entre 1961 e 2014 por meio da utilização de extremos de temperatura máxima diária, em três grandes áreas, duas ao norte e uma ao sul. Os resultados deste trabalho deixam claro que o Brasil tem sido atingido por um número consideravelmente maior de ondas de calor, a partir do ano 2000. Sendo assim, há uma real possibilidade de crescimento deste número de ondas de calor, considerando os cenários climáticos de aquecimento futuro.

Na região semiárida do Brasil, Moura (2015) registra um aumento progressivo do número, da intensidade e da duração de eventos extremos de calor, nomeadamente a partir da década de 1990. O Rio Grande do Norte segue a tendência que vem sendo observada em todo Nordeste, de verões quentes com máximas de até $3^{\circ} \mathrm{C}$ acima da média. Pesquisadores do Centro Nacional de Informações Climáticas dos Estados Unidos constataram que o mês de outubro de 2019 apresentou a maior média de temperaturas da terra e dos oceanos desde 1880. No estado, a baixa umidade do ar, entre 20 e $25 \%$, também é um fator que influencia a sensação térmica de calor durante o verão desde 2018 (Tribuna do Norte, 2019a).

\subsection{Aumento da evapotranspiração}

A evapotranspiração em regiões semiáridas é uma condição natural em virtude das altas temperaturas e incidência solar. Então, para todos os participantes, o aumento de temperatura pode intensificar esses processos no RN.

No nosso estado, a gente considera que os índices de evaporação dos reservatórios chegam até $60 \%$, uma barragem com capacidade de armazenamento de 2,4 bilhões de $m^{3}$ são evaporados enquanto a água estiver parada (Pesquisador/a, 2019).

Se nós tivermos um aumento da temperatura na nossa região, nós teremos o aumento da evaporação de água para atmosfera, isso vai limitar muito a disponibilidade hídrica, porque hoje quem mais usa água dos nossos reservatórios é o sol. E partindo do cenário que as chuvas diminuirão e a evapotranspiração vai aumentar, a disponibilidade hídrica no estado vai estar ainda mais comprometida (Pesquisador/a, 2019).

Quanto às mudanças na evapotranspiração potencial, as projeções também mostram tendências de aumento progressivo, seguindo um padrão semelhante, como a precipitação até o final deste século de acordo com o cenário RCP8.5 (IPCC, 2014).

É característica de regiões semiáridas receber precipitação abaixo da evapotranspiração potencial. Santos et al. (2010) observaram um aumento na evapotranspiração potencial média (ETPmed) do ar, nos cenários de 2050 e de 2100 , em relação à situação climática atual. Na região que compreende os Estados do Maranhão, Piauí, Ceará e Rio Grande do Norte, foram encontrados valores de ETPmed entre 1.500 e $1.700 \mathrm{~mm}$ por período. 
De acordo com Jesus (2014), climatologicamente a distribuição anual de evapotranspiração sobre o Estado do Rio Grande do Norte, utilizando dados da EMPARN (1963-2008), apresenta uma média anual de $1.600 \mathrm{~mm}$ para grande parte dos municípios da região leste, alguns na região central e poucos na região oeste; $1.200 \mathrm{~mm}$ a $1.400 \mathrm{~mm}$ em alguns municípios das regiões agreste, central e oeste; e as maiores taxas para municípios localizados na região oeste do estado, com $1.800 \mathrm{~mm}$. Os meses de outubro a janeiro representam os meses mais secos, apresentando as maiores taxas de transferência de água para a atmosfera. Na região oeste as taxas mensais de evapotranspiração chegam a ser superiores a 150 mm.mês ${ }^{-1}$.

Uma maior evapotranspiração reduz a quantidade de água no solo, mesmo que as chuvas não diminuam significativamente, e esse é um fator que dificulta o armazenamento de águas nos reservatórios do estado.

\subsection{Desertificação}

Essa também foi uma ameaça climática citada com unanimidade devido à desertificação ser resultado de processos característicos do clima semiárido e que poderão ser intensificados, considerando as projeções de aumento de temperatura. Os participantes da pesquisa acrescentam, também, algumas consequências da desertificação:

A ampliação das áreas de desertificação ocorrerá, principalmente, na região Seridó, onde alguns estudos já apontam essa tendência. Como consequência se tem a perca do solo, principalmente, se houver chuvas intensas, por causa da erosão. E esse solo pode ser transportado para reservatórios e esses ficarem assoreados (Pesquisador/a, 2019).

A desertificação é uma realidade muito latente aqui, principalmente pelas práticas de uso do solo, a gente está vivenciando ondas de propagação de incêndio (...) (Pesquisador/a, 2019).

Com esse cenário de aumento de temperatura, diminuição da precipitação e aumento nas taxas de evapotranspiração, também associado a práticas de uso de solos e à remoção da vegetação caatinga, todo o domínio climático semiárido apresenta alta susceptibilidade a processos de aridização e desertificação (Brasil, 2007).

Até o fim do século XXI, projeta-se que a vegetação semiárida tenderá a ser substituída por vegetação de terras áridas. Nas áreas mais secas, prevê-se que a mudança do clima acarrete a salinização e a desertificação (IPCC, 2007). As áreas susceptíveis à desertificação (ASD) brasileiras foram determinadas seguindo os pressupostos norteadores da $\mathrm{UNCCD}^{6}$, que propõem a adoção do índice de aridez (IA), calculado pela razão entre a precipitação pluviométrica e a evapotranspiração (Brasil, 2007).

No Brasil, há uma grande extensão territorial de ASD e para o estudo das causas e efeitos da desertificação criaram-se os Núcleos de Desertificação, que são: Gilbués (PI), Irauçuba (CE), Cabrobó $(\mathrm{PE})$ e Seridó $(\mathrm{PB} / \mathrm{RN})$. Essas áreas apresentam

\footnotetext{
6 Convenção das Nações Unidas de Combate à Desertificação UNCCD: instrumento jurídico do direito internacional, concluído pela ONU em 17 de junho de 1994, do qual o Brasil tornou-se signatário em 25 de junho de 1997.
} 
características semelhantes, tais como: irregular distribuição das precipitações pluviométricas, solos jovens e pouco desenvolvidos, recobertos por caatinga, etc. (Aquino, 2010). O Núcleo Seridó, no Rio Grande do Norte, compreende seis municípios (Rio Grande do Norte, 2010).

\subsection{Incêndios florestais}

A ameaça de incêndios florestais foi citada, principalmente, devido à grande ocorrência de episódios de incêndio no estado no período da pesquisa. Os participantes acreditam que os incêndios foram causados pelas práticas agrícolas, mas que alguns fatores climáticos podem agravar esses incêndios. Outra questão colocada é que esses incêndios podem acontecer sem interferência humana, pelas condições do clima e da vegetação.

Os incêndios que a gente está observando estão sendo causados pelas práticas agrícolas, que alguns agricultores colocam fogo para limpeza do terreno. Mas as condições do clima fazem esse fogo se espalhar por outras áreas, devido a vegetação está muito seca, a temperatura elevada... (...) E acredito que com as mudanças climáticas, o semiárido pode ficar igual ao cerrado, que acontece uma combustão natural (Pesquisador/a, 2019).

Os incêndios florestais estão numa crescente de 2017 para cá, apesar das chuvas, principalmente esse ano, a baixa humidade relativa do ar, afetou muito a região do alto oeste até chegar no Seridó, o que torna mais grave ainda pela prática de queimadas sem manejo e o fogo acaba se propagando e o incêndio fica de grande proporção. O que acaba complicando a atuação do corpo de bombeiros que tem um número de efetivos pequeno, que não é em todos os municípios também (Órgão Público, 2019).
As projeções do IPCC (2007) já indicavam que as mudanças climáticas poderiam afetar o número de incêndios ocorridos anualmente, a duração da estação de incêndios e a área queimada por incêndios, além de aumentar a intensidade do fogo. As alterações nestas propriedades do fogo significam incêndios sazonais mais frequentes e com maior intensidade e, portanto, maior potencial de incêndio.

"O clima influencia fortemente a atividade global de incêndios, e os recentes surtos de incêndios podem sinalizar mudanças pirogeográficas induzidas pelo clima" (Jolly et al., 2015, p. 1). Esses autores apresentam uma análise das tendências globais diárias do tempo de incêndio entre 1979 e 2013 e concluem que houve seis anos $(2005,2007,2009$, 2010, 2012 e 2013) em que mais de $20 \%$ da área vegetada global foi afetada por longas temporadas de incêndio (Jolly et al., 2015).

Flannigan et al. (2009) confirmam, em uma análise de estudos sobre a atividade global de incêndios florestais, que inúmeras pesquisas sugerem que a área queimada e a ocorrência de incêndios aumentarão com um clima mais quente e as estações de incêndio serão mais longas.

Dados do Instituto Nacional de Pesquisas Espaciais - INPE - mostram que no Rio Grande do Norte, entre janeiro e novembro de 2019, foram registrados em torno de 500 focos de incêndios florestais, sendo 98,2\% em áreas de vegetação caatinga. Na serra onde se localiza o Santuário do Lima, em Patu, um incêndio florestal durou seis dias, até ser controlado pelo corpo de bombeiros do estado. A vegetação seca e os fortes ventos facilitam a propagação rápida do fogo e dificultam o controle (Tribuna do Norte, 2019b). 


\subsection{Elevação do nível do mar}

A elevação do nível do mar foi citada com unanimidade pelos participantes como uma ameaça climática que já está causando impactos no estado. Para eles, é bem claro que está havendo o avanço do mar e as cidades costeiras estão bastante expostas devido à proximidade das construções com a faixa de praia. A erosão foi o principal impacto mencionado.

A população se aproxima demais da costa e tem suas casas e seus empreendimentos ameaçados pela erosão e, também, soterradas pelas dunas. (...) no estuário do rio Apodi/Mossoró e no Piranhas Açu há um desenvolvimento de atividades econômicas muito forte, se houver um aumento do nivel do mar, essas atividades serão comprometidas (Pesquisador/a, 2019).

Em relação à elevação global no nível do mar prevista para 2100 , espera-se uma variação de aumento entre $26 \mathrm{~cm}$ e $55 \mathrm{~cm}$ no melhor cenário e entre $52 \mathrm{~cm}$ e $98 \mathrm{~cm}$ no pior cenário (IPCC, 2013). A elevação do nível do mar continuará para além de 2100, mesmo que o aquecimento global seja limitado a $1,5^{\circ} \mathrm{C}$ no século XXI (IPCC, 2019).

Uma elevação de 50 centímetros no nível do Atlântico poderia consumir 100 metros de praia, em regiões como o Norte e o Nordeste. No Nordeste, várias regiões costeiras estão suscetíveis à erosão, pela falta de rios capazes de abastecer o mar com sedimentos (Marengo, 2007).

A zona sedimentar costeira do Estado do Rio Grande do Norte perfaz uma extensão de $410 \mathrm{~km}$ de costa, constituída predominantemente por praias arenosas e falésias ativas (Vital et al., 2006).
Vários estudos (Nicolodi \& Petermann, 2010; Lima, 2010; Franco et al., 2012) confirmam que os municípios litorâneos do RN têm vivenciado a intensificação da erosão marinha nas últimas décadas. Marés altas, erosão e inundações são relatos antigos há pelo menos quatro décadas, quando também começou a se observar o avanço do nível do mar. Com o aquecimento global e a elevação do nível do mar, esses problemas estão sendo mais frequentes e mais intensos.

\subsection{Perdas de biodiversidade}

Alguns participantes mencionaram que essas ameaças climáticas apresentadas anteriormente provocam impactos sobre a biodiversidade e os ecossistemas, com a perda e a extinção de espécies.

A fauna e flora serão bastante impactadas pelas mudanças climáticas. Há uma perda irreparável, por conta dos incêndios florestais, pelos processos de desertificação... A gente sabe que a vegetação da caatinga, também os animais, são bem adaptadas às condições de seca, mas ninguém sabe até que ponto, né? Acho que pode haver um grande desequilibrio na cadeia alimentar (Órgão Público, 2019).

Projeta-se que $18 \%$ dos insetos, $16 \%$ das plantas e $8 \%$ de vertebrados percam metade de sua amplitude geográfica determinada pelo aquecimento global de $2^{\circ} \mathrm{C}$, bem como haverá a perda irreversível de muitos ecossistemas marinhos e costeiros (IPCC, 2019).

Apesar de não haver estudos suficientes relacionados à perda de espécies no Brasil, essa é uma tendência climática de alta probabilidade de ocorrência em regiões de clima semiárido, considerando 
o que é colocado por MA (2005), que os processos acelerados de desertificação podem, adversamente, afetar a biodiversidade. Segundo o mesmo autor, os principais componentes que provocam a perda da biodiversidade são a destruição de habitat, a introdução de espécies invasoras e as mudanças na temperatura, que podem gerar o desequilíbrio e a mudança na estrutura da comunidade vegetal e da diversidade biológica.

Face ao exposto, várias ameaças climáticas, aliadas a ações antrópicas, estão expondo a população e outros sistemas da região semiárida do $\mathrm{RN}$ ao risco. O aumento da temperatura global, o agravamento de extremos climáticos, o aumento de áreas desertificadas, são situações que agravam os problemas já existentes nessa região.

A Tabela 1 apresenta uma síntese do nível de concordância entre a literatura discutida e as ameaças percebidas pelos entrevistados. Na tabela, a coluna 1 apresenta as nove ameaças climáticas, as colunas 2 e 3 apresentam o nível de concordância para ocorrência dessas ameaças nas escalas global e regional, respectivamente, e na coluna 4 é apresentada a probabilidade de ocorrência das ameaças identificadas na área de estudo.

\section{Considerações finais}

Os avanços tecnológicos e na ciência climática permitem afirmar que as mudanças climáticas são evidentes e que são causadas pelas atividades humanas. Essas mudanças impõem uma série de riscos e podem intensificar riscos já existentes. Especificamente em regiões semiáridas, um aumento de temperatura representa uma série de riscos, como a maior ocorrência de eventos extremos de secas, o aumento de áreas desertificadas e a propagação de incêndios florestais.

TABELA 1 - Ameaças climáticas identificadas pelos entrevistados e sua probabilidade de ocorrência, a partir da concordância com as projeções globais e regionais.

\begin{tabular}{cccc}
\hline Ameaças identificadas & $\begin{array}{c}\text { (Escala Global) } \\
\text { CONCORDÂNCIA }\end{array}$ & $\begin{array}{c}\text { (Semiárido Brasileiro) } \\
\text { CONCORDÂNCIA }\end{array}$ & $\begin{array}{c}\text { (Região Semiárida do RN) } \\
\text { PROBABILIDADE }\end{array}$ \\
\hline Aumento da Temperatura & Alta & Alta & Alta \\
Extremos de seca & Média & Alta & Alta \\
Extremos de chuvas & Média & Média & Alta \\
Extremos de calor & Média & Alta & Alta \\
Evapotranspiração & Média & Alta & Alta \\
Desertificação & Média & Alta & Alta \\
Incêndios & Média & Alta & Alta \\
Elevação do nível do mar & Alta & Média & Alta \\
Perda de biodiversidade & Alta & Alta & Alta \\
\hline
\end{tabular}

FONTE: Dados da pesquisa, 2020.

NOTA: Níveis de concordância - baixa (nenhum estudo aponta), média (em escala global apenas algumas regiões e em escala regional apenas alguns estados), alta (estudos concordam que a ameaça afeta a escala em análise). 
Este artigo teve como objetivo compreender como alguns formadores de opinião e tomadores de decisão percebem os riscos das mudanças climáticas sobre a região semiárida do Rio Grande do Norte. Para isso, utilizou-se a categoria "ameaça climática" para esta análise como um elemento condicionante ao risco. Sendo assim, nas falas dos participantes foi possível identificar que a percepção que se tem dos riscos das mudanças climáticas é que haverá a piora de ameaças já existentes, ou seja, o agravamento de alguns fenômenos climáticos naturais ou causados pelo efeito das atividades humanas e seu modo apropriação do território.

Foram discutidas nove ameaças percebidas pelos participantes da pesquisa. Com a análise e a discussão dessas ameaças, é possível observar que há uma forte concordância entre as tendências cli- máticas globais e regionais presentes na literatura, bem como existe alta probabilidade de ocorrência na área estudada, considerando as projeções climáticas e os fenômenos climáticos que já acontecem historicamente.

Sendo assim, esta análise permitiu lançar um olhar sobre os riscos climáticos aos quais a região semiárida brasileira está/estará exposta e compreender se há a aceitação e a percepção dos riscos das mudanças climáticas. A partir dessa discussão, será possível, na continuidade desta pesquisa, compreender como as pessoas ou sistemas dessa região tornam-se vulneráveis aos riscos climáticos, bem como os mecanismos de resposta que vêm se dando para a minimização dos impactos das ameaças climáticas aqui discutidas.

Ambiente-MMA, fevereiro 2007. Disponível em: $<$ http:// mudancasclimaticas.cptec.inpe.br/ rmclima/pdfs/prod_probio/Relatorio_3.pdf>. Acesso em: jan. 2019.

ANA - Agência Nacional de Águas. Região Hidrográfica Atlântico Nordeste Oriental. 2017. Disponível em: <https:// www.ana.gov.br/textos-das-paginas-do-portal/regiao-hidrografica-atlantico-nordeste-oriental> Acesso em: abr. 2019.

Aquino, C. M. S. Estudo da degradação/desertificação no núcleo de São Raimundo Nonato - Piauí. São Cristóvão, Tese (Doutorado em Geografia) - Universidade Federal de Sergipe, 2010.

Aquino, J. R. de. O PIB e as desigualdades econômicas no RN. Jornal O Mossoroense. Mossoró/RN, 13/07/2016, p. 2. Disponível em: <http://www.omossoroense.com.br/ joacir-rufino-de-aquino-o-pib-e-asdesigualdades-economicas-no-rn/>. Acesso em: jul. 2020. 
Aquino, J. R. de; Nunes, E. M. Desempenho recente e perspectivas da economia do Rio Grande do Norte no século XXI. Revista BNB Conjuntura Econômica, n. especial, 2019. Disponível em: https://www.bnb.gov.br/documents/80223/6034753/2019_CJES_19RN.pdf/67d45680-673f-db90-fc13-b0b3f37d2 $-\overline{f c} 4$

Barbieri, M. D.; Ferreira, L. C.; Barbi, F. Governando as mudanças climáticas. Ideias, 9(2), 71-98, 2018. doi: 10.20396/ideias.v9i2.8655192

Bardin, L. Análise do discurso. Lisboa: Edições 70, 1977.

Beck, U. Sociedade de risco: rumo a uma outra modernidade. São Paulo: Ed. 34, 2010.

Bitencourt, D. P.; Fuentes, M. V.; Maia, P. A.; Amorim, F. T. Frequência, duração, abrangência espacial e intensidade das ondas de calor no Brasil. Revista Brasileira de Meteorologia, 31(4), 2016. Disponível em: https://www.scielo. br/scielo.php?pid=S0102-77862016000800506\&script=sci_abstract\&tlng=pt

Bodansky, D. The history of the global climate change regime. In: Luterbacher, U.; Sprinz, D. F. International relations and global climate change. Cambridge, Massachusetts; London: The MIT Press, 2001. p. 23-40.

Brasil. Governo Federal. Lei $n^{\circ}$ 12.187, de 29 de dezembro de 2009. Institui a Política Nacional sobre Mudança do Clima - PNMC. Brasília, 2009.

Brasil. Ministério do Meio Ambiente - MMA. Atlas das áreas susceptíveis à desertificação do Brasil. Secretaria de Recursos Hídricos, Universidade Federal da Paraíba; Marcos Oliveira Santana, organizador. Brasília: MMA, 2007.

Brasil. Ministério do Meio Ambiente. Método de Análise Participativa de Risco à Mudança do Clima. Ministério do Meio Ambiente, Secretaria de Biodiversidade. Brasília-DF, 2018.

Brasil. Plano Nacional de Adaptação à Mudança do Clima. Versão Pós-Consulta Pública/ Ministério do Meio Ambiente, Secretaria de Mudanças Climáticas e Qualidade Ambiental. Brasília-DF, 2016.

Cardona, O. D. Evaluación de la amenaza, la vulnerabilidad y el riesgo. Elementos para el ordenamiento y la planeación del desarrollo. En: Maskrey, A. (Comp.). Los desastres no son naturales. La RED, Tercer Mundo Editores, 1993.

Cardona, O. D. The Need for Rethinking the Concepts of Vulnerability and Risk from a Holistic Perspective: A Necessary Review and Criticism for Effective Risk Management. In: Bankoff, G.; Frerks, G.; Hilhorst, D. Mapping Vulnerability: Disasters, Development and People. London: Earthscan Publishers, 2004.

Carter, T. R. General guidelines on the use of scenario data for climate impact and adaptation assessment. Intergovernmental Panel on Climate Change - Task group on data and scenario support for impact and climate assessment (TGICA), 2007.

Carvalho, C. P. O. O novo padrão de crescimento no Nordeste semiárido. Revista Econômica do Nordeste, Fortaleza/ CE, 45(3), 160-184, jul./set. 2014. Disponível em: https:// ren.emnuvens.com.br/ren/article/view/125

Cirilo, J. A.; Montenegro, S. M. G. L.; Campos, J. N. B. A questão da água no semiárido brasileiro. In: Bicudo, C. E. de M.; Tundisi, J. G.; Scheuenstuhl, M. C. B. (Orgs.). Águas do Brasil: análises estratégicas. v. 1, São Paulo: Instituto de Botânica, 2010. p. 81-91.

Diniz, M. T. M.; Pereira, V. H. C. Climatologia do estado do Rio Grande do Norte, Brasil: sistemas atmosféricos atuantes e mapeamento de tipos de clima. Boletim Goiano de Geografia, 35(3), 488-506, 2015. Disponível em: https:// www.revistas.ufg.br/index.php/bgg/article/view/38839

Flannigan, M. D.; Krawchuk, M. A.; De Groot, W. J.; Wotton, B. M.; Gowman, L. M. Implications of changing climate for global wildland fire. Int. J. Wildland Fire, 18, 483-507, 2009. Disponível em: https://www.researchgate. net/publication/236246525_Implications_of_changing_climate_for_global_Wildland_fire

Forgus, R. H. Percepção: o processo básico do desenvolvimento cognitivo. São Paulo: Herder, 1971.

Franco, C. G. M.; Amaro, V. E.; Souto, M. V. S. Prognóstico da erosão costeira no Litoral Setentrional do Rio Grande do Norte para os anos de 2020, 2030 e 2040. Revista de Geologia, 25(2), 37-55, jul.-dez. 2012. Disponível em: http://www.periodicos.ufc.br/geologia/article/view/3055 
Franco, M. L. P. B. Análise de conteúdo. Brasília: Plano Editora, 2003.

Garjulli, R. Os recursos hídricos no semiárido. Ciência e Cultura, 55(4), 38-39, out/dez. 2003. Disponível em: http://cienciaecultura.bvs.br/scielo.php?pi$\mathrm{d}=$ S0009-67252003000400021\&script=sci_arttext\&tlng=pt

Giddens, A. A política da mudança climática. 1. ed. Rio de Janeiro: Zahar, 2010.

Hansen, J. E.; Sato, M. Paleoclimate implications for human-made climate change. In: Berger A.; Mesinger, F.; Sijacki, D. (Eds.). Climate Change: Inferences from Paleoclimate and Regional Aspects. Wien: Springer-Verlag, 2012. 270 p. doi: 10.1007/978-3-7091-0973-1_2

Hogan, D. J. Demographic Aspects of Global Environmental Change: What is Brazil's Contribution? In: Hogan, D. J.; Tolmasquim, M. T. Human Dimensions of Global Environmental Change: Brazilian Perspectives. Rio de Janeiro: Academia Brasileira de Ciências, 2001. p. 15-41.

IBGE - Instituto Brasileiro de Geografia e Estatística. Anuário Estatístico do Brasil. v. 70. Rio de Janeiro: IBGE, 2010.

IPCC - Intergovernmental Panel on Climate Change. Climate Change 2001: The Scientific Basis-Contribution of Working Group 1 to the IPCC Third Assessment Report of the Intergovernmental Panel on Climate Change. Cambridge: Cambridge Univ. Press, 2001.

IPCC - Intergovernmental Panel on Climate Change. Climate Change 2014: Impacts, Adaptation, and Vulnerability. Contribution of Working Group II to the Fifth Assessment Report of the Intergovernmental Panel on Climate Change. Edited by C. B. Field et al. Cambridge/New York: Cambridge University Press/IPCC, 2014.

IPCC - Intergovernmental Panel on Climate Change. Fifth Assessment Report: Climate Change 2013. Intergovernmental Panel on Climate Change. Cambridge: Cambridge University Press, 2013.

IPCC - Intergovernmental Panel on Climate Change. Four Assessment Report: Climate Change 2007: Impacts, Adaptation, and Vulnerability. Group II to the Fifth Assessment Report of the Intergovernmental Panel on Climate Change (IPCC). Cambridge: Cambridge Univ. Press, 2007.
IPCC - Intergovernmental Panel on Climate Change. Sumário para Formuladores de Políticas. Versão em português publicada pelo MCTIC em julho de 2019, Brasil.

Jesus, E. dos S. Avaliação da evapotranspiração na microrregião do Seridó: uma contribuição metodológica. Natal, Tese (Doutorado) - Universidade Federal do Rio Grande do Norte, 2014.

Jolly, W.; Cochrane, M.; Freeborn, P.; Holden, Z. A.; Brown, T. J.; Williamson, G. J.; Bowman, D. M. J. S. Climate-induced variations in the global fire hazard from 1979 to 2013. Nat. Commun., 6, 7537, 2015. Disponível em: https://www. nature.com/articles/ncomms8537

Kasperson, J. X.; Kasperson, R. E.; Pidgeon, N. E.; Slovic, $\mathrm{P}$. The social amplification of risk: assessing fifteen years of research and theory. In: Pidgeon, N.; Kasperson, R. E. E.; Slovic, P. (Eds.). The Social Amplification of Risk. Cambridge: Cambridge University Press, 2003. p. 13-46.

Kates, R. W.; Hohenemser, C. E.; Kasperson, J. X. Perilous Progress: Managing the Hazards of Technology. Boulder, CO: Westview Press, 1985.

Kern, K.; Alber, G. Governing Climate change in cities: Modes of urban Climate governance in multi-level systems. In: Proceedings of Competitive Cities and Climate Change, OECD Conference, Milão, Itália, 2008. p. 171-192.

Knutti, R.; Furrer, R.; Tebaldi, C.; Cermak, J.; Meehl, G. A. Challenges in combining projections from multiple climate models. Journal of Climate, 23(10), 2739-2758, 2010. doi: 10.1175/2009JCLI3361.1

Kundzewicz, Z.W. et al. Freshwater resources and their management. In: Parry, M. L.; Canziani, O. F.; Palutikof, J. P.; van der Linden, P. J.; Hanson, C. E. (Eds.). Climate Change 2007: Impacts, Adaptation and Vulnerability. Contribution of Working Group II 106 to the Fourth Assessment Report of the Intergovernmental Panel on Climate Change. Cambridge, UK: Cambridge University Press, 2007. p. 173-210.

Leiserowitz, A. Climate Change Risk Perception and Policy Preferences: The Role of Affect, Imagery, and Values. Climatic Change, 77(1-2), 45-72, 2006. doi: 10.1007/ s10584-006-9059-9 
Lima, E. Q. de. Vulnerabilidade ambiental da zona costeira de Pititinga, Rio do Fogo, Rio Grande do Norte. Natal, Dissertação (Mestrado) - Universidade Federal do Rio Grande do Norte, 2010.

Lindoso, D. P. Adaptação à mudança climática: ciência, política e desenvolvimento sustentável. Clima com Cultura Cientifica - Pesquisa, Jornalismo e Arte, ano 2, 2, 2015. Disponível em: https://www.scielo.br/scielo.php?script=sci_arttext\&pid=S0103-40142016000300025

Lucena, R. L.; Cabral Júnior, J. B.; Steinke, E. T. Comportamento Hidroclimatológico do Estado do Rio Grande do Norte e do Município de Caicó. Revista Brasileira de Meteorologia, 33(3), 485-496, 2018. Disponível em: https://www.scielo.br/scielo.php?script=sci_abstract\&pi$\mathrm{d}=\mathrm{S} 0102-77862018000300485 \& \operatorname{lng}=\mathrm{en} \& \mathrm{nrm}=\mathrm{iso} \& \operatorname{lng}=\mathrm{pt}$

MA - Millennium Ecosystem Assessment. Ecosystems and Human well-Being: Desertification synthesis. Washington-DC: World Resources Institute, 2005.

Marandola Jr., E. Tangenciando a vulnerabilidade. In: Hogan, D. J.; Marandola Jr., E. (Orgs.). População e mudança climática: dimensões humanas das mudanças ambientais globais. Campinas: Núcleo de Estudos de População (NEPO/Unicamp); Brasília: UNFPA, 2009. p. 29-52.

Marandola Jr.; Hogan, D. J. As dimensões da vulnerabilidade. São Paulo em Perspectiva, São Paulo: Fundação Seade, 20, 33-43, 2006. Disponível em: https://www.forumjustica. com.br/wp-content/uploads/2014/10/Vulnerabilidade.pdf

Marengo, J. A. Mudanças climáticas globais e seus efeitos sobre a biodiversidade: caracterização do clima atual e definição das alterações climáticas para o território brasileiro ao longo do século XXI. V. 1, 2. ed. Brasília: Ministério do Meio Ambiente, 2007.

Marengo, J. A. O futuro clima do Brasil. Revista USP, 103, 25-32, 2014. Disponível em: http://www.revistas.usp.br/ revusp/article/download/99280/97696/

Marengo, J. A. Vulnerabilidade, impactos e adaptação à mudança do clima no semiárido do Brasil. Parcerias Estratégicas, Brasília, 13(27), 149-176, 2008. Disponível em: http://seer.cgee.org.br/index.php/parcerias_estrategicas/ article/view/329
Martins, M. C. H.; Fatigati, F. L.; Vespoli, T. C.; Martins, L. C.; Pereira, L. A. A.; Martins, M. A.; Saldiva, P. H. N.; Braga, A. L. F. Influence of socioeconomic conditions on air pollution adverse health effects in elderly people: an analysis of six regions in São Paulo, Brazil. Journal of Epidemiology \& Community Health, 58(1), 2004. doi: 10.1136/jech.58.1.41

Martins, R. D.; Ferreira, L. C. Opportunities and constraints for local and subnational climate change policy in urban areas: insights from diverse contexts. Int. J. Global Environmental Issues, 11(1), 37-53, 2011. doi: 10.1504/ IJGENVI.2011.04025

Martins, R. D.; Ferreira, L. C. The research on human dimensions of global environmental change in Latin America: Looking back, moving forward. International Journal of Climate Change Strategies and Management, 2(3), 264-280, 2010. doi: 10.1108/17568691011063042

McBean, G. Climate change and extreme weather: a basis for action. Natural Hazards, Springer Netherlands, 31(1), 177190. 2004. doi: 10.1023/B:NHAZ.0000020259.58716.0d

Minayo, M. C. S.; Sanches, O. Quantitativo-Qualitativo: oposição ou complementaridade? Caderno de Saúde Pública, 9(3), 239-262, 1993. doi: 10.1590/S0102311X1993000300002

Moura, M. Anomalias das temperaturas extremas do ar em Fortaleza, Ceará, Brasil. Revista Brasileira de Geografia Física, 8(6), 1588-1600, 2015. Disponível em: https://periodicos.ufpe.br/revistas/rbgfe/article/view/233676

Nicolodi, J. L.; Petermann, R. M. Mudanças Climáticas e a Vulnerabilidade da Zona Costeira do Brasil: aspectos ambientais, sociais e tecnológicos. Revista da Gestão Costeira Integrada, 10(2),151-177, 2010. Disponível em: https:// www.aprh.pt/rgci/pdf/rgci-206_Nicolodi.pdf

Nímer, E. Um modelo metodológico da classificação de climas. Revista Brasileira de Geografia - IBGE, Rio de Janeiro, ano 41, 4, 59-89, out./dez. 1979.

Nobre, C. A.; Reid, J.; Veiga, A. P. S. Fundamentos científicos das mudanças climáticas. São José dos Campos, SP: Rede Clima/INPE, 2012. 44 p.

Nunes, E. Geografia Física do Rio Grande do Norte. 1. ed. Natal: Imagem Gráfica, 2006. 
Nunes, L. H. Mudanças climáticas, extremos atmosféricos e padrões de riscos a desastres hidrometeorológicos. In: Hogan, D. J.; Marandola Jr., E. (Orgs.). População e mudanças climáticas: dimensões humanas das mudanças ambientais globais. Campinas: NEPO/Unicamp; Brasília: UNFPA, 2009.

Obermaier, M.; Rosa, L. P. Mudança climática e adaptação no Brasil: uma análise crítica. Estudos Avançados, 27(78), 155-176, 2013. doi: 10.1590/S0103-40142013000200011

Ojima, R.; Marandola Jr., E. Mudanças climáticas e as cidades: novos e antigos debates na busca da sustentabilidade urbana e social. São Paulo: Blucher, 2013.

ONU - Organização das Nações Unidas. $A$ ONU e a mudança climática. Disponível em: $<$ https://nacoesunidas.org/ acao/mudanca-climatica/>. Acesso em: jan. 2019.

PBMC - Painel Brasileiro de Mudanças Climáticas. Base Científica das Mudanças Climáticas. Contribuição do Grupo de Trabalho 1 do Painel Brasileiro de Mudanças Climáticas ao Primeiro Relatório de Avaliação Nacional sobre Mudanças Climáticas. Organização de T. Ambrizzi \& M. Araujo. Rio de Janeiro: Coppe/Universidade Federal do Rio de Janeiro, 2013.

Rio Grande do Norte. Secretaria de Recursos Hídricos - SERHID. Programa de Ação Estadual de Combate à Desertificação e Mitigação dos Efeitos da Seca no Estado do Rio Grande do Norte - PAE/RR. Natal/RN, 2010.

Santos, D. N. dos; Silva, V. P. R. da; Sousa, F. A. S.; Silva, R. A. Estudo de alguns cenários climáticos para o Nordeste do Brasil. Revista Brasileira de Engenharia Agricola e Ambiental, 14(5), 492-500, 2010. Disponível em: https:// www.scielo.br/pdf/rbeaa/v14n5/a06v14n5.pdf

Simões, A. F.; Kligerman, D. C.; La Rovere, E. L.; Maroun, M. R., Barata, M.; Obermaier, M. Enhancing adaptive capacity to climate change: the case of smallholder farmers in the Brazilian semi-arid region. Environmental Science \& Policy, 13, 801-808, 2010. doi: 10.1016/j.envsci.2010.08.005

Speth, J. D.; Tchernov, E. The role of hunting and scavenging in Neandertal procurement strategies. Neandertals and modern humans in Western Asia. Boston, MA: Springer, 2002. p. 223-239.
SUDENE - Superintendência do Desenvolvimento do Nordeste. Nota Técnica $N^{o}$ 05/2017/CGDS/DPLAN/SUDENE. Recife: SUDENE, 2017, 5 p. Disponível em: $<\mathrm{http} / / /$ sudene. gov.br/images/2017/arquivos/NOTA_T\%C3\%89CNICA_n\%C2\%BA_05_-_2017.pdf>. Acesso em: jan. 2019.

Tribuna do Norte. Incêndios Florestais no RN. Publicado em 31/10/2019b. Disponível em: <http://www.tribunadonorte. com.br/noticia/corpo-de-bombeiros-militar-combate-15-inca-ndios-em-24h-no-rn/463555>. Acesso em: mar. 2019.

Tribuna do Norte. Previsão de verão ainda mais quente no RN. Publicado em 21/12/2018. Disponível em: <http:// www.tribunadonorte.com.br/noticia/previsa-o-a-de-vera-o-ainda-mais-quente-no-rio-grande-do-norte/433812> Acesso em: mar. 2019.

Tribuna do Norte. Verão três graus mais quente no RN. Publicado em 27/11/2019a. Disponível em: <http://www.tribunadonorte.com.br/noticia/vera-o-devera-ser-mais-quente-ata-tra-s-graus-no-rn/465835>. Acesso em: mar. 2019.

UNFCCC - United Nations Framework Convention on Climate Change. Full Text of Convention. 1992. Disponível em: <https://unfccc.int/resource/docs/convkp/conveng. pdf $>$. Acesso em: jan. 2019.

UNISDR - United Nations Office for Disaster Risk Reduction. Gender perspective: Working together for disaster risk reduction. Geneva: UNISDR, 2007.

UNISDR - United Nations Office for Disaster Risk Reduction. Global Assessment Report on Disaster Risk Reduction: Risk and poverty in a changing climate. United Nations International Strategy for Disaster Reduction. Geneva, Switzerland: UNISDR, 2009.

Veyret, I. Os riscos: o homem como agressor e vítima do meio ambiente. 2. ed. São Paulo: Contexto, 2013. 315 p.

Villas Bôas, B. Extrema pobreza avança e é recorde em 9 estados. Valor Econômico, São Paulo, 9/10/2018. Disponível em: $<$ https://www.valor.com.br/node/5912587>. Acesso em: jul. 2020.

Vital, H.; Silveira, I. M.; Amaro, V. E.; Melo, F. T. L.; Souza, F. E. S.; Chaves, M. S.; Lima, Z. M. C.; Frazão, E. P.; Tabosa, W. F.; Araújo, A. B.; Souto, M. V. S. Rio Grande 
do Norte. Erosão e progradação do litoral brasileiro. V. 1. Z Zanirato, S. H.; Ramires, J. Z. S.; Amicci, A. G. D.; Brasília: Ministério do Meio Ambiente, 2006. p. 155-172. Ribeiro, Z. M.; Ribeiro, W. C. Sentidos do Risco: Inter-

Weart, S. The Discovery of Global Warming. Cambridge, MA: Harvard University Press, 2003.

Yearley, S. Sociology and Climate Change after Kyoto: What Roles for Social Science in Understanding Climate Change? Current Sociology, 57(3), 389-405. 2009. doi: 10.1177/0011392108101589 pretações Teóricas. Revista Bibliográfica de Geografía y Ciencias Sociales, XIII(785), 2008. Disponível em: https://www.researchgate.net/profile/Jane_Ramires/publication/239812516_Sentidos_do_risco_interpretacoes_teoricas/links/5bc36830299bf1004c5f332f/Sentidos-do-risco-interpretacoes-teoricas 